\title{
Reuna
}

\section{LÓGICA INSTITUCIONAL DA SUSTENTABILIDADE NO CONTEXTO DE ENERGIA SOLAR}

\author{
INSTITUTIONAL LOGIC OF SUSTAINABILITY IN THE SOLAR ENERGY SECTOR
}

http://dx.doi.org/10.21714/2179-8834/2020v25n1p35-53

\author{
Mariana Fernandes Alves \\ Universidade de Fortaleza, Brasil. \\ E-mail: marifalves@edu.unifor.br \\ Minelle Enéas da Silva \\ Universidade de Fortaleza, Brasil. \\ E-mail: minele.adm@gmail.com
}

Submissão: 12 Set. 2019 Publicação: 4 Mai. 2020. Sistema de avaliação: Double blind review. Centro Universitário UNA, Belo Horizonte - MG, Brasil. Editor geral: Prof. Dr. Thiago Soares Nunes

Este artigo encontra-se disponível nos seguintes endereços eletrônicos:

http://revistas.una.br/index.php/reuna/article/view/1087

http://dx.doi.org/10.21714/2179-8834/2020v25n1p35-53

\section{Resumo}

Os debates acerca da sustentabilidade numa perspectiva setorial apesar de crescentes ainda requerem o surgimento de estudos que explorem, principalmente, campos organizacionais para compreender as práticas de sustentabilidade inseridas em relacionamentos entre os atores que o compõe, como é o caso da cadeia de suprimento. Buscando contribuir com esta lacuna, o objetivo dessa pesquisa foi compreender como práticas de sustentabilidade estão relacionadas à formação da lógica institucional na cadeia de suprimento de energia solar. Para tanto, foi realizada uma pesquisa qualitativa e descritiva conduzida sob a forma de um estudo de caso. Por meio de entrevistas e pesquisa documental, a coleta de dados ocorreu entre novembro de 2017 e fevereiro de 2018. Utilizando-se as categorias do construto lógica institucional da sustentabilidade (sequência de eventos, mudança de estrutura, empreendedor institucional e prática de sustentabilidade) foi possível discutir a visão de diferentes atores. A partir das análises foram identificados eventos que dão indícios de mecanismos de mudança que são estimulados principalmente por parte do governo, o que pode facilitar a formação de uma lógica institucional de sustentabilidade. Sobre práticas de sustentabilidade identificou-se que nem sempre os atores compreendem a sustentabilidade com o mesmo significado. Os resultados dão suporte para o avanço de pesquisas sobre o conceito de sustentabilidade e sua aplicabilidade em diversos contextos da área de gestão.

Palavras-chave: Sustentabilidade; Prática; Campo Organizacional; Lógica institucional da sustentabilidade; Energia solar.

\section{Abstract}

The debates about sustainability in a sectorial perspective, although growing, still require the emergence of studies that explore, mainly, organizational fields to understand the practices of sustainability inserted in relationships between the actors 
that compose it, such as the supply chain. The aim of this research was to understand how sustainability practices are related to the formation of institutional logic in the solar energy supply chain. For that, a qualitative and descriptive research was conducted as a case study. Through secondary data and interviews, data collection took place between November 2017 and February 2018. Using the categories of the institutional logic of sustainability (sequence of events, change of structure, institutional entrepreneur and sustainability practice) it was possible to discuss the vision of different actors. From the analyzes, events were identified that give indications of mechanisms of change that are stimulated mainly by the government, which can facilitate the formation of an institutional logic of sustainability. Regarding sustainability practices, it has been identified that actors do not always understand sustainability with the same meaning. The results support the progress of research on the concept of sustainability and its applicability in several management contexts.

Keywords: Sustainability; Practice; Organizational Field; Institutional logic of sustainability; Solar energy.

\section{Introdução}

Vários debates vêm sendo realizados sobre sustentabilidade, principalmente quando se fala em contribuições para a literatura dos negócios. Todavia, há a necessidade de aprofundar o conhecimento teórico e empírico sobre visões mais práticas, que consigam demonstrar e explicar como a realidade se apresenta. Neste contexto, diversas visões teóricas podem ser utilizadas e podem contribuir para tanto (SILVA; FIGUEIREDO, 2020). Uma das formas de identificar empiricamente esta realidade se dá por uma análise institucional, o que pode ocorrer pela construção de uma Lógica Institucional (LI). Para reduzir esta lacuna, esta pesquisa propõe pesquisar a formação de práticas de sustentabilidade no contexto de energia solar, à luz da Lógica Institucional de Sustentabilidade (LIS) (SILVA; FIGUEIREDO, 2017).

Diferentes abordagens têm surgido usadas na tentativa de buscar maior explicação e compreensão no debate acerca da sustentabilidade (SARTORI et al., 2014). No campo das organizações, a discussão sobre sustentabilidade foi introduzida pelo conceito baseado no Triple Bottom Line (TBL), composta por três dimensões que se relacionam: econômica, ambiental e social (ELKINGTON, 2002). Neste sentido, os discursos de gestores sobre sustentabilidade tangem a busca por desenvolver práticas nessas dimensões, para obtenção de uma imagem positiva da empresa, razão pela qual o estudo de suas interações ou harmonia demonstra-se essencial (CLARO et al., 2008; SILVA et al., 2011). Tais discussões precisam ser institucionalizadas e influenciam a dinâmica das organizações (KULAK et al., 2019).

Debates e discussões sobre a formação de práticas de sustentabilidade podem utilizar-se da lógica institucional (LI) como lente de análise, para uma melhor compreensão e esclarecimentos sobre sustentabilidade e suas interações com indivíduos e organizações (RECHENE et al., 2018; SILVA; NASCIMENTO, 2017). No que tange às lógicas institucionais, estas são compreendidas como "conjuntos de práticas materiais e construções simbólicas” (FRIEDLAND; ALFORD, 1991, p. 248), que são considerados na formação da identidade coletiva que é socialmente construída para as práticas e comportamentos que foram institucionalizadas (THORNTON; OCASIO, 2008; THORNTON et al., 2012). 
De acordo com as considerações realizadas, utiliza-se nessa pesquisa a LIS como suporte teórico, mais especificamente, pretende-se compreender práticas de sustentabilidade aplicadas à cadeia de suprimento (CS) de energia solar buscando contribuir empiricamente para o avanço do debate sobre o tema. Estudos sobre CS de energia solar têm observado diversas perspectivas, entretanto é necessário desenvolvê-los de forma a inserir a sustentabilidade como forma de gestão (ARMIN RAZMJOO et al., 2019; FAGUNDES et al., 2016; FERNANDO et al., 2018). Assim, utiliza-se como campo organizacional nesta pesquisa a CS de energia solar no Ceará. Como organização (empresa focal) estão as empresas vendedoras de placas solares e como clientes encontram-se os consumidores de placas solares.

A partir das considerações aqui realizadas, o objetivo dessa pesquisa foi compreender como práticas de sustentabilidade estão relacionadas à formação da lógica institucional na cadeia de suprimento de energia solar. O Brasil apresenta grande potencial em relação ao mundo na busca por fontes de energia solar, destacando-se o Ceará como um local privilegiado, devido a grande incidência dos raios solares. Desse modo, justifica-se a pesquisa pelo seu potencial contributivo para - mercado e para a administração pública. Com esta pesquisa, podem surgir informações para mudanças macro no setor estudado.

Como melhor forma de compreender a presente pesquisa, além desta parte introdutória são apresentados os elementos teóricos utilizados como suporte para o desenvolvimento do objetivo e realização da pesquisa de campo. Para tanto, apresenta-se o conceito da LIS e sua contribuição para estudar de sustentabilidade. $\mathrm{Na}$ seção seguinte, estão os procedimentos metodológicos que nortearam esta pesquisa. As análises apresentam os resultados advindos da pesquisa de campo, 0 que facilitou o entendimento das contribuições desta pesquisa. Por fim, estão apresentadas as considerações finais desta pesquisa.

\section{Referencial teórico}

Esta seção apresenta os fundamentos teóricos para a pesquisa, contemplando os temas: sustentabilidade em cadeias de suprimento (SCS), lógica institucional e lógica institucional de sustentabilidade (LIS).

\subsection{Sustentabilidade em cadeia de suprimento}

A sustentabilidade e o desenvolvimento sustentável são temas de extrema importância nos estudos científicos por estarem relacionadas ao desenvolvimento econômico que não agrida a natureza e as gerações futuras. Além disso, nas palavras de Soares (2017), trata-se de matérias que não possuem limites territoriais, sendo de significância global. Ao se estudar a sustentabilidade e o desenvolvimento sustentável, estuda-se primordialmente o equilíbrio que deve existir entre o avanço econômico e a preocupação com meio ambiente, pois economia depende da natureza, tratando-se esta da principal via de extração da matéria-prima (SARTORI et al., 2014).

O conceito de sustentabilidade está atrelado à ideia de continuidade, permanência e restauração, palavras que dão enfoque ao que deve ser observado na relação entre meio ambiente e humanidade. Desse modo, entende-se que a 
sustentabilidade já se tornou assunto popular entre os estudiosos, e passou a ser preocupação global, sendo foco de outros diversos encontros promovidos por entidades internacionais de direito público (FEIL; SCHREIBER, 2017). A partir da visão de Elkington (2002), criou-se o tripé da Sustentabilidade, equalizando três aspectos principais: econômico, social e ambiental. Essa noção tripartite sugere que a sustentabilidade seja vista a partir de três pilares que devem relacionar-se integralmente a fim de alcançar o desenvolvimento sustentável (MUNCK et al.; 2008). O que reflete em adoções sustentáveis nas estratégias das cadeias produtivas, como uma forma de diferenciação de produtos (ALVES et al., 2018; CRUZ et al., 2017; SANTOS et al., 2019).

Nesse sentido, evidencia-se que a sustentabilidade pode se aproximar aos estudos organizacionais, seja no formato individual ou a partir de relacionamentos e uma deles refere-se à CS. Enquadra-se a esta ideia o conceito de cadeia de suprimento, que, de acordo com Ballou, Gilbert e Mukherjee (2000), trata-se do agrupamento das atividades associadas com a transformação e o fluxo de bens e serviços, incluindo o fluxo de informações, para o suprimento de matérias-primas até o usuário final. Desta feita, entende-se por cadeia de suprimento as inter-relações de empresas necessárias para fabricação e venda de um produto ou serviço (MENTZER et al., 2001; MIN et al., 2019).

Considerando os conceitos aproximados, entende-se que a sustentabilidade em cadeias de suprimento pode ser entendida como "uma abordagem institucional socialmente construída que cria valor de negócio no longo prazo para diferentes stakeholders na cadeia de suprimento, considerando todas as dimensões da sustentabilidade" (SILVA, 2015, p. 63). Esta perspectiva entende CS tanto como estratégia quanto como prática. Isso ocorre, segundo Silva and Figueiredo (2020), uma vez que todos os membros da CS assumem a sustentabilidade como uma meta que não é um fim por ela mesmo, mas continua em constante mudança ao longo do tempo. Tal perspectiva pode ser observada sob a visão de uma trajetória, sendo que a sustentabilidade não é o fim, mas a jornada a ser percorrida (SILVESTRE, 2015).

Considerando esta visão, destaca-se que para esta pesquisa considera-se apenas o relacionamento entre dois elos da cadeia de suprimento, ou seja, uma relação diádica que representa a cadeia de suprimento direta (AZEVEDO et al., 2018; MENTZER et al., 2001). Neste sentido, para Maloni e Benton (1997), a construção de relacionamentos interorganizacionais diminui as barreiras entre os agentes que compõem a díade, impedindo que as organizações existam de forma isolada, pois elas dependem de seus colaboradores, fornecedores e consumidores, dependendo de cada caso. Considerando a visão a-teórica que vem sendo observada na literatura de SCS (TOUBOULIC; WALKER, 2015), a presente pesquisa se aprofunda na visão teórica da lógica institucional buscando contribuir para um entendimento mais claro sobre a realidade.

\subsection{Formação da Lógica Institucional}

Ao falar de institucionalização, segundo Carvalho et al. (1999) é imprescindível citar o estudo de Philip Selznick (1957). O autor norte-americano foi pioneiro no estudo institucional e diferenciou organizações de instituições, explanando o evento da institucionalização. Desta feita, transcrevem-se as palavras de Carvalho et al. (1999, p.1 ), que ao debater sobre a influência do autor em introduzir um modelo instituticional 
e interpretar as organizações influenciadas pelo contexto, afirma que tudo está envolto num "'processo de institucionalização', [que] pode ser sintetizado num aspecto: os valores substituem os fatores técnicos na determinação das tarefas organizativas. Para Alves (2019), a perspectiva institucional auxilia a identificar valores fundamentais que formam práticas em determinado contexto.

Estudos baseados na teoria institucional são vistos como facilitadores no entendimento das organizações (STÀL, 2015). A teoria institucional explica práticas adotadas pelas organizações como forma de legitimação. Para o estudo da abordagem institucional deve-se buscar entender o conceito de campo organizacional. Assim sendo, DiMaggio e Powell (2005, p.76) entendem "por campo organizacional aquelas organizações que, em conjunto, constituem uma área reconhecida da vida institucional". Segundo Thornton e Ocasio (2008, p.109), este não é um conceito tão simples de ser definido, ao menos que seja definida, por exemplo, "como uma comunidade geográfica, uma comunidade posicional (seria o caso de CEOs da Fortune 500), ou redes interorganizacionais".

Ao seguir a perspectiva desses últimos autores, percebe-se que o campo organizacional tem relação direta com o conceito de lógica institucional. Neste sentido, para Friedland e Alford (1991, p.232) as "instituições são potencialmente contraditórias e, portanto, tornam possíveis as múltiplas lógicas para indivíduos e organizações". Por essa razão, a interferência entre diferentes lógicas institucionais, poderá ser responsável pelo comportamento de atores sociais inseridos num determinado contexto, podendo influenciar num processo de mudança (COSTA et al., 2013). Tal perspectiva pode ser utilizada para o estudo de diferentes contextos que vão desde economia compartilhada (RECHENE et al., 2018) até o estudo de cadeias de suprimento (SILVA; NASCIMENTO, 2017) como nesta pesquisa.

Para uma melhor compreensão da temática, a LI pode ser entendida como uma teoria e um método de análise para entender as influências da cultura na cognição e comportamentos do indivíduo (THORNTON et al., 2005). Para os autores, cultura, valores, crenças e intenções influenciam nas organizações, portanto na mudança institucional. A LI é compreendida como "a teoria dos efeitos institucionais e preveem o tipo ideal de mudança e estabilidade que provavelmente ocorrerão" (THORNTON et al., 2005, p. 11). É entendida como a construção coletiva de um conjunto de práticas e comportamentos em um dado campo organizacional, via recursividade, considerando-se tanto aspectos materiais como simbólicos.

Para examinar a LI, deve-se considerar alguns aspectos centrais, sendo eles: o sistema econômico, as fontes de identidade, as fontes de legitimidade, as fontes de autoridade, as bases da missão, as bases da atenção, as bases da estratégia, a lógica de investimento, os mecanismos de governança, o empreendedorismo institucional, a sequência de eventos e a mudança de estrutura (THORNTON et al., 2005; THORNTON; OCASIO, 1999). Entretanto, o foco dos estudos de LI têm se concentrado nos três últimos aspectos - empreendedorismo institucional, sequência de eventos e mudança de estrutura (SILVA, 2015).

Inicialmente são considerados empreendedores institucionais aqueles que identificam novos caminhos em seu setor de atuação, contribuindo para a mudança institucional (THORNTON et al., 2005). Em continuidade, sequência de eventos "refere-se a como a ordem dos principais eventos leva a uma mudança na percepção cognitiva de eventos que prefigura uma mudança na lógica institucional" (THORNTON 
et al., 2005, p. 8). Já a mudança de estrutura é analisada a partir da sequência de eventos que a influenciou e ocorre quando indivíduos e estruturas são forçados a mudar para uma nova estrutura (THORNTON et al., 2005). Ou seja, para analisar essa dimensão são considerados os eventos ocorridos a partir de recorte temporal, que poderá ser influenciador na mudança de estrutura. Vale destacar que essa mudança poderá ocorrer a partir de pressões. Apesar destas considerações, para esta pesquisa buscou-se foco nas práticas de sustentabilidade (ver KALUK et al., 2019), o que auxiliou na construção da LIS.

\subsection{Lógica Institucional da Sustentabilidade}

Buscando estudar a formação de uma lógica alinhada com o atual momento em que a sustentabilidade surge como elemento central em diversas relações de mercado e sociedade, Silva e Figueiredo (2017) apresentaram o conceito de lógica institucional da sustentabilidade (LIS). Tomando como base os três atributos já mencionados: o empreendedorismo institucional, a sequência de eventos e a mudança de estrutura, os autores adicionaram a dimensão "prática da sustentabilidade" como mais um atributo. Com uma visão macro sobre a temática, entende-se por LIS como o reflexos de ações de sustentabilidade no campo organizacional (SILVA; FIGUEIREDO, 2017). Para os autores, primeiro isso ocorre nas práticas dos agentes que compõem a organização, e então são repassadas para o macro contexto da estrutura que passa a orientar novas práticas.

Entendendo-se que o desenvolvimento sustentável pode ser visto como um conjunto de práticas que norteia a mudança para uma nova formatação da organização (MORAIS et al., 2014), percebe-se que a sustentabilidade pode ser integrada na construção de novas práticas de sustentabilidade nos relacionamentos nas organizações. No entanto, vale ressaltar que nem sempre essas práticas formam uma LI (SILVA, 2015). A lógica institucional é instituída pela representação de padrões construídos social e historicamente, partindo de valores, crenças e práticas dos indivíduos, ao produzirem continuamente sua substância material (THORNTON; OCASIO, 1999), coordenando a realidade organizacional entre os membros da organização (LAWRENCE; PHILLIPS, 2004).

Nesse sentido, toma-se a discussão sobre a formação de uma LI voltada à sustentabilidade em cadeias de suprimento, na qual as práticas de sustentabilidade são construídas e institucionalizadas. Para tanto, a LIS é vista como uma abordagem que ajuda no entendimento do processo de mudança. Essa busca compreender como a sustentabilidade vem sendo praticada em um dado campo organizacional. $O$ processo de mudança para uma nova estrutura ocorre a partir de uma sequência de eventos ao longo do tempo, no qual as ações de empreendedores institucionais geram a mudança de estrutura, ou seja, são atores que implementam estratégias de sustentabilidade, no qual as práticas de sustentabilidade são inseridas e institucionalizadas nesse contexto (SILVA; FIGUEIREDO, 2020), levando assim a uma nova estrutura.

A prática de sustentabilidade parte do pressuposto que a sustentabilidade "surge e ressurge, recursivamente, enquanto resultado das ações e intenções socialmente construídas por agentes sociais" (SILVA; FIGUEIREDO, 2017), inseridas em diversos contextos e que é possível compreendê-la como de fato ela se estabelece em uma dada conjuntura. Nesse sentido, resumidamente, tem-se que a dimensão 
sequência de eventos traz uma melhor compreensão dos acontecimentos. Na dimensão mudança de estrutura inicial para uma $\mathrm{LI}$, percebe-se que a sequencia temporal de eventos influencia na mudança para uma nova estrutura, pois os eventos ocorridos podem gerar mudança de estrutura. Nesse sentido, por intermédio do empreendedor institucional, é possível verificar como as ações de sustentabilidade são implementadas. Por fim, a mudança de estrutura ocorre e a prática de sustentabilidade é institucionalizada.

De acordo com Silva e Nascimento (2017), torna-se clara a possibilidade de estudo da dinâmica institucional da sustentabilidade em cadeias de suprimento a partir da LIS. Desse modo devem ser estudadas as quatro dimensões: Empreendedor Institucional; Sequencia de Eventos; Mudança de Estrutura e Práticas de Sustentabilidade. Tais dimensões são facilitadores no processo da inserção da prática de sustentabilidade em CS. Assim sendo, o Quadro 1 indica como seria possível o estudo da LIS na cadeia de suprimento:

Quadro 1 - Elementos para pesquisa da lógica institucional da sustentabilidade
\begin{tabular}{|l|l|}
\hline \multicolumn{1}{|c|}{ Dimensões } & \multicolumn{1}{c|}{ Descrição } \\
\hline Empreendedor Institucional & $\begin{array}{l}\text { Aquele responsável e motivador da mudança, desenhando os } \\
\text { incentivos internos para tanto. }\end{array}$ \\
\hline Sequência de eventos & $\begin{array}{l}\text { Os principais eventos que facilitaram a mudança, existência de } \\
\text { pressões externas e incentivos. }\end{array}$ \\
\hline Mudança de estrutura & $\begin{array}{l}\text { Envolve características da cadeia de suprimento no que se } \\
\text { refere a sua orientação, a continuidade, a colaboração, a gestão } \\
\text { de risco (BESKE; SEURING, 2014). Bem como o estilo de } \\
\text { relacionamento. }\end{array}$ \\
\hline Práticas de sustentabilidade & $\begin{array}{l}\text { O significado dados pelos atores ao tema, critérios baseados no } \\
\text { TBL, criação de rotinas e procedimentos, comunicação com } \\
\text { stakeholders. }\end{array}$ \\
\hline
\end{tabular}

Fonte: Adaptado de Rechene et al. (2018).

Como se observa no quadro anterior, tais elementos de pesquisa foram utilizados como categorias base para o desenvolvimento desta pesquisa. Sabendo que a cadeia de suprimento surge como campo organizacional e que a sustentabilidade pode ser nesta disseminada (ALVES, 2019; SAYED et al., 2017), fazse necessário investigar como ocorrem as relações entre os atores envolvidos na cadeia, facilitando a inserção da prática de sustentabilidade nas organizações (CLARO, 2004). A seção a seguir detalha o processo de coleta de dados.

\section{Procedimentos Metodológicos}

$\mathrm{Na}$ busca pelo atendimento do objetivo proposto, entende-se que a qualidade de um estudo de campo implica que o pesquisar detalhe a metodologia e o delineamento da pesquisa (GODOY, 2006). Assim, quanto à abordagem, a pesquisa classifica-se como qualitativa (CRESWELL, 2007), considerando-se a incipiência do assunto abordado. A pesquisa qualitativa é definida por Denzin e Lincoln (2000) como uma atividade situada, colocando o pesquisador no mundo, constituindo num campo de práticas materiais e interpretativas que tornam o mundo visível.

Segundo seus objetivos, a pesquisa caracteriza-se como um estudo descritivo, que tem como finalidade descrever características de determinado fenômeno, a partir de uma temática pouco explorada (GIL, 2010). Dessa forma, o estudo deve buscar compreender o objeto proposto na pesquisa (VERGARA, 2010), expondo as práticas 
de sustentabilidade constituídas no campo, descrevendo, assim, suas principais especificidades. Toma-se como método de pesquisa a estratégia de estudo de caso desenvolvida por meio de uma abordagem investigativa empírica que analisa as relações de um determinado fenômeno, sem abrir mão do contexto ambiental na qual está ocorrendo (YIN, 2015). O método de estudo de caso é uma estratégia que busca examinar um fenômeno contemporâneo dentro de seu contexto, e que se mostra adequado em um modelo de investigação de natureza qualitativa; a coleta de informações pode ser realizada a partir de documentos, arquivos, gravações, entrevistas (YIN, 2015).

Para a presente pesquisa assume-se como nível de análise o campo organizacional aqui representado pela cadeia de suprimento de energia solar no Ceará. Durante a pesquisa foram usadas mais especificamente, as unidade de análise díades existentes nessa CS.

Os sujeitos da pesquisa são formados por três empresas fornecedoras de placas solares, (E1, E2 e E3), quatro empresas compradoras de placas solares (C1, $\mathrm{C} 2$, C3e C4), e três membros de incentivo a aquisição de placas solares, denominados na pesquisa de atores não tradicionais (ANT1, ANT 2 e ANT 3). Todos os sujeitos estão localizados no Estado do Ceará. O processo de identificação da pesquisa se deu por intermédio de pesquisas sobre empresas fornecedoras de placas solares e seus respectivos clientes. Além de identificar organizações que fomentam o setor de energia solar no Estado do Ceará.

A coleta de dados ocorreu entre novembro de 2017 e fevereiro de 2018. A primeira etapa da coleta de dados consiste em um levantamento documental para amparar a compreensão do objeto de estudo. Primeiramente foi realizada uma pesquisa a fim de buscar informações sobre a evolução histórica da energia elétrica no mundo, bem como buscas a fim de identificar eventos ligados à energia solar a nível mundial. Em seguida, buscaram-se documentos sobre a sequência de eventos no Brasil sobre energia solar. Seguindo de busca de eventos sobre energia solar no Estado do Ceará,

$\mathrm{Na}$ segunda etapa foram realizadas entrevistas individuais com os atores envolvidos, com duração média de 43 minutos. Para tanto foram contatados todos os sujeitos antes apresentados. Ratifica-se que a díade foi selecionada, a fim de analisar a relação entre a empresa focal e clientes, visto que a relação diádica é o relacionamento entre duas partes (PEREIRA; BELLINI, 2006), que interagem num determinado contexto (ANTONELLO et al., 2010). Os respondentes da pesquisa foram os responsáveis pelos setores estratégicos das organizações, ou seja, responsáveis pelas decisões. Optou-se por não revelar os nomes das empresas, a fim de preservar sua identidade.

Finalizada a coleta de dados, partiu-se para a análise dos dados. Nesse momento da pesquisa utilizou-se a Análise de Conteúdo (BARDIN, 2009), com o propósito de encontrar elementos associados às quatro dimensões da LIS. As entrevistas foram transcritas, organizadas e estruturadas em categorias de análise, identificadas a partir do referencial teórico, quais sejam: sequência de eventos, empreendedorismo institucional, mudança de estrutura e práticas de sustentabilidade. Vale salientar que para entender tais práticas, buscou-se identificar qual o significado apresentado pelos respondentes. Portanto, usando o TBL como referência, buscouse nas análises identificar a existências de tais dimensões. 


\section{Análise dos dados}

Conforme estudo da Associação Brasileira de Energia Solar Fotovoltaica (ABSOLAR, 2018), a energia solar representa $48 \%$ de todo o investimento mundial em energia renovável. Nesse sentido, a energia solar fotovoltaica está sendo considerada grande aliada da sustentabilidade. Buscando entender a formação da LIS na CS de energia solar, é imprescindível compreender o processo de uma formação da lógica, a partir do contexto selecionado. Logo, as análises a seguir buscam indícios dessa formação.

\subsection{Constituição do Campo Organizacional}

O embasamento para desenvolver as análises desse estudo está na institucionalização. De acordo com DiMaggio e Powell (1983), o campo organizacional é uma área reconhecida da vida institucional que inclui fornecedores-chave, consumidores de recursos e produtos, agências reguladoras e outras organizações que produzem produtos ou serviços similares. Nesse sentido, o campo organizacional da CS de energia solar é formado por diversos atores que facilitam investigar como os fatores institucionais operam nesse campo (Quadro 2).

O potencial técnico de energia fotovoltaica no Brasil é maior que o somatório do potencial técnico de todas as outras fontes de energias do país (SEBRAE, 2017). De acordo com dados, estima-se que a energia fotovoltaica representará $32 \%$ da matriz em 2040 e dessa capacidade 75\% será geração distribuída. Para apoiar a pesquisa empírica, foi realizada uma pesquisa documental, ampliando as evidencias provenientes de outras fontes (YIN, 2015), na qual foi mapeado o campo organizacional. Nesse sentido, o quadro apresenta a descrição dos autores envolvidos no campo organizacional da presente pesquisa.

\begin{tabular}{|l|l|}
\multicolumn{2}{|c|}{ Quadro 2 - Descrição dos atores do campo organizacional } \\
\hline Empresas Fabricantes & $\begin{array}{l}\text { Empresas fornecedoras de insumos e matéria-prima para construção kits } \\
\text { voltaicos. }\end{array}$ \\
\hline $\begin{array}{l}\text { Empresas } \\
\text { Fornecedoras }\end{array}$ & Empresas que revendem os kits voltaicos para o cliente final \\
\hline Clientes & $\begin{array}{l}\text { Pessoas ou empresas que adquirem os kits voltaicos, passando a gerar } \\
\text { sua própria energia, que é lançada na rede. }\end{array}$ \\
\hline Portal Solar & $\begin{array}{l}\text { Maior site de energia solar do Brasil, no qual traz informações sobre } \\
\text { fornecedores e informações sobre energia solar. }\end{array}$ \\
\hline ANEEL & $\begin{array}{l}\text { Agência Nacional de Energia Elétrica que faz as regras para toda a rede } \\
\text { de fornecimento de energia funcione, desde a geradora até a sua tomada. }\end{array}$ \\
\hline SindiEnergia & $\begin{array}{l}\text { Sindicato das Indústrias de Energia e de Serviços do Setor Elétrico que } \\
\text { representa a indústria de energia do Estado do Ceará. }\end{array}$ \\
\hline FIEC & $\begin{array}{l}\text { Principal entidade de representação das indústrias do estado brasileiro do } \\
\text { Ceará, que estimula o desenvolvimento de negócios. }\end{array}$ \\
\hline Governo & $\begin{array}{l}\text { O governo tem a finalidade de executar as políticas e diretrizes oriundas } \\
\text { da Secretaria do Desenvolvimento Econômico, no qual assume o papel de } \\
\text { regulamentar as regras sobre o uso de energia solar }\end{array}$ \\
\hline Serviços de Apoio & $\begin{array}{l}\text { Apoiar a implantação da tecnologia de placas solares em pequenos } \\
\text { negócios, acompanhando o desempenho e o ganho de competitividade, } \\
\text { além de promover a sustentabilidade. }\end{array}$ \\
\hline Bancos & $\begin{array}{l}\text { Fomentar e apoiar a inovação através de uma linha de financiamento para } \\
\text { sistemas de energia fotovoltaica para as empresas Nordestinas. }\end{array}$ \\
\hline
\end{tabular}

REUUNA, Belo Horizonte - MG, Brasil, v. 25, n. I, p. 35-53, Jan. - Mar. 2020 - ISSN 2179-8834 
Organização do Terceiro Setor
Organização não governamental do campo popular democrático que atua apoiando comunidades através de projetos para implantação de placas solares com a finalidade de autonomia local.

Fonte: Dados da pesquisa (2018).

De acordo com o Quadro 2, verifica-se os vários atores que compõem o campo organizacional da CS de energia solar. Além dos atores acima, de acordo com pesquisa do Sebrae (2017), foram mapeados 69 fontes de financiamento, dentre eles: Banco Nacional de Desenvolvimento Econômico (BNDES), Financiadora de Estudos e Projetos (FINEP), Agência Nacional de Energia Elétrica (ANEEL), Fundos Constitucionais, Bancos Multilaterais, Bancos Comerciais, Agências de Crédito à Exportação, Agência de Fomento Estadual, Crédito Via Fornecedor, Mercado Financeiro. Essas instituições tem papel fundamental no desenvolvimento da cadeia. Considerando os atores apresentados, entende-se haver maior interação entre as empresas fornecedoras e os clientes. Como dito anteriormente, a presente pesquisa teve como o foco a díade - fornecedor e cliente. Nesse sentindo cada ator teve seu papel na compreensão da formação de uma nova lógica institucional.

\subsection{Ações/Evidências de Práticas de Sustentabilidade}

Percebe-se o papel do Governo como principal fomentador para o início de mudanças de hábitos no contexto analisado. Nota-se que a partir da regulamentação do uso de energia solar, novos comportamentos surgindo, ajudando assim, o início de uma institucionalização de novas práticas, facilitando então, a formação da LIS. Apesar do entendimento de sustentabilidade não está em total consonância com o tripé de sustentabilidade proposto por Elkington (2002), as ações do dia a dia dos entrevistados trazem a preocupação relacionadas à alguma das três dimensões, destacando-se a preocupação ambiental (Quadro 3). Tal resultado se assemelha ao que foi identificado por Cruz et al. (2017) e Morais et al. (2014).

\section{Quadro 3 - Evidências de Sustentabilidade para os diferentes atores pesquisados}

\begin{tabular}{|c|c|}
\hline Atores & Descrição \\
\hline C1 & $\begin{array}{l}\text { A empresa evita comprar produtos que demoram muito a se degradar; Lixo } \\
\text { orgânico; ação de lavar as lixeiras, para não usar sacolas de plásticos; } \\
\text { seleção do lixo. }\end{array}$ \\
\hline $\mathrm{C} 2$ & $\begin{array}{l}\text { Uso de tanques ecológicos pela empresa e seu fornecedor, mas de maneira } \\
\text { coercitiva.. }\end{array}$ \\
\hline C3 & $\begin{array}{l}\text { Descarte de mercadoria; separação do lixo; venda de papel e plástico; o fundo } \\
\text { arrecadado é destinado às ações sociais; trabalhos comunitários; coleta } \\
\text { seletiva; } 5 S \text {; controle de redução de água. }\end{array}$ \\
\hline E1 & $\begin{array}{l}\text { Empresa gera sua própria energia; bastante área verde; a empresa acredita } \\
\text { que precisa melhorar nesse aspecto. }\end{array}$ \\
\hline E2 & $\begin{array}{l}\text { Para a empresa, as ações estão ligadas à própria venda do produto, que é a } \\
\text { sustentabilidade. }\end{array}$ \\
\hline E3 & Sem resposta \\
\hline ANT1 & Ações próprias na área socioambiental; como projeto papel zero. \\
\hline ANT2 & $\begin{array}{l}\text { A empresa mantém toda uma politica de sustentabilidade; politica de coleta } \\
\text { seletiva; gestão de resíduos sólidos; mobilidade urbana; prédio sustentável; } \\
\text { programas para conscientizar funcionários sobre sustentabilidade; projetos de } \\
\text { ações sociais para a comunidade. }\end{array}$ \\
\hline ANT3 & $\begin{array}{l}\text { Reaproveitamento de papel; separação do lixo; projetos nas comunidades de } \\
\text { utilização de água e redução de dejetos das fossas; projeto de bioconstrução; } \\
\text { projetos para evitar contaminação do lençol freático; projeto de busca de }\end{array}$ \\
\hline
\end{tabular}

REUINA, Belo Horizonte - MG, Brasil, v. 25, n. I, p. 35-53, Jan. - Mar. 2020 - ISSN 2179-8834 
alternativas para captação de agua; campanhas de educação ambiental ligada à proteção dos manguezais.

Fonte: Dados da pesquisa (2018).

Segundo os dados, existe entendimento de que existem ações voltadas à sustentabilidade em relação com o uso de energia solar. Verificou-se que existe relação entre as mudanças de estrutura e as ações de sustentabilidade (cf. SAYED et al., 2017), evidenciadas nas falas de alguns entrevistados: C2: "[...]a sustentabilidade está bem na nossa missão né... nós somos um dos Pioneiros dentre as distribuidoras a colocar placa, mas é como eu te falei a questão, é cultural nossa mesmo". ANT1: "[...] com essa geração a gente consegue melhorar a eficiência nossa reduz custo. Então tem impacto no tripé da sustentabilidade né? No... No social, no ambiental e na visão das empresas, no econômico!". Nesse sentido, a existência de ações de sustentabilidade auxiliam a formação das práticas de sustentabilidade (SILVA; FIGUEIREDO, 2020), as quais podem vir a ser institucionalizadas (ALVES, 2019; KALUK et al., 2019; SILVA; NASCIMENTO, 2017), facilitando a formação da LIS (SILVA, 2015).

\subsection{Formação da LIS}

Para a formação da LIS é necessário analisar as inter-relações de quatro dimensões - sequência de eventos, empreendedor institucional, mudança de estrutura e prática de sustentabilidade (SILVA; FIGUEIREDO, 2017). Com foco inicial na sequência de eventos, buscou-se analisar o que aconteceu ao longo da história para a efetividade de ações no setor (cf. RECHENE et al., 2018). O presente estudo limita-se à análise da energia solar, dentre as fontes renováveis, é a que, conforme informações do Portal Solar (2018), apresenta o maior crescimento mundial. O grande potencial do Brasil em energia solar é inegável, considerando a grande incidência desta fonte no território nacional. Assim, para compreender os eventos relacionados à energia solar no mundo, foram mapeados eventos ligados a esse assunto, no qual se constatou que o uso de placas solares surgiu a nível mundial desde a década de 1950. Nesse sentido os eventos relacionados ao contexto de energia solar são relevantes para melhor entendimento do assunto abordado na pesquisa.

Para tanto é preciso observar se as dimensões estão sendo observadas ao longo do tempo para a formação dessa nova lógica. Com foco inicial na sequência de eventos, busca-se analisar o que aconteceu ao longo da história para a efetiva de ações no setor. Nesse sentido, a partir de pesquisa documental foram detectados eventos desde o ano 2000 no contexto de energia solar no Brasil e no Ceará. A partir desta análise, notou-se que a frequência de eventos apresenta baixa possibilidade de ser retomada, visto que se trata de eventos referentes à legislação e criação de programas de incentivos governamentais para o uso de energia solar. Apesar da baixa frequência, os eventos, em sua maioria, são considerados de médio impacto, pois tais acontecimentos poderão impactar na formação de práticas de sustentabilidade na cadeia (cf. SILVA, 2015), visto os envolvidos poderão converter suas ações à práticas de sustentabilidade.

Outra análise considera que a grande maioria dos eventos tem escala externa, concluindo que a lógica poderá ser alterada por fatores externos à CS, visto que lógica está em construção. Em adição, apresenta-se a pressão sofrida ou exercida por cada evento, no qual 11 dos 20 eventos mapeados apresentaram pressões. Para Brito e 
Berardi (2010) e Kulak et al. (2019), tais pressões são fontes de mudanças sofridas por algum ator que compõe o campo organizacional. Nesse sentido, esses eventos podem influenciar nas práticas de sustentabilidade na CS de energia solar. A partir das informações apresentadas, constata-se que no ano de 2015 teve uma maior ocorrência dos eventos. Percebe-se ainda que, nesse período, estímulos em relação à tributação, através de incentivos por parte do governo, no qual fomenta a CS de energia solar. $\mathrm{Na}$ fala de alguns entrevistados compreendem-se essa discussão:

\begin{abstract}
Até o ano retrasado eu não via como viável ou então viável o sistema fotovoltaico financeiramente por que o governo do estado do Ceará ele cobrava o ICMS e injetável e voltava para a unidade consumidora e depois no final do ano retrasado foi isento. (E2).

O que é importante são as políticas de incentivo né? Aí vem a questão de como é que o governo federal tem estimulado isso, o governo do estado também junto com Federal Como É Que Tem trabalhado subsídios ou isenções para estimular essa cadeia produtiva expandir mais né? (ANT1).
\end{abstract}

Considerando a ideia de Empreendedor Institucional, na relação da díade da CS de energia solar percebe-se claramente o papel do governo como empreendedor institucional na formação da LIS, como na pesquisa de Rechene et al. (2018). Observou-se que aspectos ligados à sustentabilidade estão vinculados às leis, resoluções e decretos. Nesse sentido, observa-se que o governo incentiva, apoia e utiliza a energia solar. Essa regulamentação é vista de forma positiva pelos entrevistados. Por exemplo, o entrevistado E1 declara que "a regulamentação é a forma que o governo tem de mapear, por uma questão de saúde da rede". Para E2 "[...] teve até um programa do governo agora: Luz para todos! Né? Que tinham locais que não tinham luz na comunidade e eles deram um quitizinho de energia solar. " Desta forma percebe que o entrevistado E2 aceita essa discussão.

Quanto à mudança de estrutura, percebe-se que 9 dos 20 eventos influenciaram a mudança de estrutura. Percebe-se ainda que, 5 dos eventos observados ao longo do período, estão completamente alinhados com a escala, 0 impacto e as pressões, corroborando ainda mais para essa mudança de estrutura. Para análise dos dados foi observado o alinhamento entre a mudança de estrutura que afetou a CS. Logo analisando aqueles eventos que tem afetam na estrutura e que foco na CS, de 9 eventos que mudaram a estrutura, 7 afetam especificamente a cadeia de suprimento de energia solar (Quadro 4).

\title{
Quadro 4 - Eventos que afetaram a cadeia de suprimento
}

\begin{tabular}{|c|l|l|}
\hline Ano & \multicolumn{1}{|c|}{ Eventos } & \multicolumn{1}{c|}{ Mudança de Estrutura } \\
\hline 2004 & $\begin{array}{l}\text { Redução das tarifas de uso dos } \\
\text { sistemas elétricos de } \\
\text { transmissão e de distribuição. }\end{array}$ & $\begin{array}{l}\text { Através da redução das tarifas de uso dos sistemas } \\
\text { elétricos de transmissão e de distribuição, aplicáveis aos } \\
\text { empreendimentos com base em fontes solares, mudou a } \\
\text { relação de produção e consumo, afetando a CS. As } \\
\text { estratégias das empresas poderão se modificar e isso vai } \\
\text { gerar uma nova dinâmica de mercado. }\end{array}$ \\
\hline 2009 & $\begin{array}{l}\text { Através da criação do fundo do FIES, os envolvidos na } \\
\text { CS de energia solar passarão a ter incentivos para } \\
\text { instalação, operação e utilização de usinas, mudando a } \\
\text { relação de produção e consumo, ou seja, afetando a CS. } \\
\text { Observa-se que mudam as relações entre as pessoas, } \\
\text { tendo uma lógica mais transacional, facilitando a criação } \\
\text { de novas transações. }\end{array}$ \\
\hline
\end{tabular}




\begin{tabular}{|c|c|c|}
\hline 2012 & $\begin{array}{l}\text { Publicação da resolução } 482 \text { da } \\
\text { ANEEL, que regulamentou a } \\
\text { micro e minigeração de energia. }\end{array}$ & $\begin{array}{l}\text { O setor foi reconceituado, pois traz a possibilidade de } \\
\text { novos atores na CS, no caso, clientes domésticos, } \\
\text { havendo assim a participação de novos atores na cadeia. } \\
\text { Através da regulamentação, abre-se a possibilidade de } \\
\text { outras fontes de energias renováveis, trazendo uma nova } \\
\text { perspectiva ambiental, econômica e social. Além de } \\
\text { mudar a relação de compra e venda. Há um } \\
\text { compartilhamento de recursos, visto que a geração de } \\
\text { cada um é jogado na rede e apenas parte dele volta para } \\
\text { o consumidor final, como forma de créditos. }\end{array}$ \\
\hline 2015 & $\begin{array}{l}\text { Concessão à isenção do ICMS } \\
\text { nas operações relativas à } \\
\text { circulação de energia elétrica } \\
\text { que utiliza fontes com base } \\
\text { solar. }\end{array}$ & $\begin{array}{l}\text { A partir do momento que governo isenta o ICMS, as } \\
\text { empresas podem se reposicionar estrategicamente, } \\
\text { trazendo novas estratégias em relação ao preço, por } \\
\text { exemplo. }\end{array}$ \\
\hline 2015 & $\begin{array}{l}\text { ANEEL publica a resolução } 687 \text {, } \\
\text { trazendo novas possibilidades à } \\
\text { utilização de fontes de energia } \\
\text { renovável pelo consumidor. }\end{array}$ & $\begin{array}{l}\text { A partir dessas novas possibilidades de distribuição, são } \\
\text { inseridos novos stakeholders na CS, poderá mudar a } \\
\text { relação de compara e veda, afetando diretamente a CS. } \\
\text { Através possibilidade de outras fontes de energias } \\
\text { renováveis, apresenta-se uma nova perspectiva } \\
\text { ambiental, econômica e social. }\end{array}$ \\
\hline 2015 & $\begin{array}{l}\text { Desoneração de PIS e COFINS } \\
\text { que incide sobre a geração } \\
\text { distribuída de energia solar. }\end{array}$ & $\begin{array}{l}\text { Altera a relação de compra e venda, poderá afetar a CS, } \\
\text { visto que vai ser mais barato para o cliente final. Da } \\
\text { mesma forma como no ICMS, como vai desonerar PIS e } \\
\text { COFINS, as empresas fabricantes poderão trazer novas } \\
\text { estratégias de preços. }\end{array}$ \\
\hline 2017 & $\begin{array}{l}\text { Instalação, no Ceará, da } \\
\text { primeira fábrica de produção de } \\
\text { painéis fotovoltaicos, inserindo } \\
\text { um fornecedor local no estado. }\end{array}$ & $\begin{array}{l}\text { A partir da instalação dessa fábrica, insere-se um } \\
\text { fornecedor local de placas solares, podendo alterar a CS. }\end{array}$ \\
\hline
\end{tabular}

Fonte: Dados de pesquisa (2018)

Constatou-se, a partir dos eventos históricos pesquisados, que a publicação da norma 482, em 2012, intensificou as mudanças neste setor. Essa norma regulamenta a micro e minigeração de energia, que é caracterizada pela instalação de pequenos geradores domésticos que utilizam fontes renováveis, instituindo o sistema de compensação de energia elétrica. $O$ decreto traz regras para a conexão dos sistemas de energia solar fotovoltaica na rede elétrica, estabelecendo diretrizes para que um gerador possa usufruir créditos em outra unidade consumidora ou consórcios possam ser constituídos, longe de seus locais de consumo, definindo percentual da energia destinada a cada unidade que o compõe.

A partir de 2012, os eventos estão ligados direta ou indiretamente à práticas de sustentabilidade na CS de energia solar no estado do Ceará, a exemplo da Resolução 687, criada pela ANEEL, em 2015, que atualiza a Resolução 482, trazendo novas possibilidades à utilização de fontes de energia renovável pelo consumidor, quais sejam: Geração compartilhada, Autoconsumo remoto e Empreendimento com múltiplas unidades consumidoras. Ou seja, são inseridos novos stakeholders na cadeia de suprimento, o que poderá mudar a relação de compara e venda, afetando diretamente a CS. Essa mudança de estrutura é evidenciada na fala do entrevistado C3: "É nós geradores, né? Nós uma empresa que tem essas placas solares e somos geradores e a própria Enel né? Porque como a gente não gera, não armazena energia, o que a gente faz joga ela na rede também né? (C3)."

A Geração Compartilhada ocorre quando dois ou mais consumidores se unem para instalar um micro ou minigerador e compartilham o crédito gerado por ele, através REULA, Belo Horizonte - MG, Brasil, v. 25, n. I, p. 35-53, Jan. - Mar. 2020 - ISSN 2179-8834 
de consórcio ou cooperativa. Já o Auto Consumo Remoto é a possibilidade de um consumidor instalar micro e minigerador diferente do local de onde reside para utilizar créditos gerados para abater do seu consumo. Vale destacar, que a partir do Quadro 5 , que as relações entre os atores da CS de energia solar, são apensas transações comerciais. Tal constatação apresenta as achados da contribuição teórica, como já mencionado anteriormente, que incluiu a micro prática Estilos de Relacionamentos na macro prática Gestão. Tal afirmação é constatada nas falas de 3 entrevistados:

\footnotetext{
[...]tanto é que a gente liga e solicita uma visita deles de manutenção, de limpeza, para que eles possam nos acompanhar ou as vezes a gente tem alguma dúvida, sobre como é que acompanha esta produção. (C1).

[...]como eu falei é uma relação comercial normal: Telefone, email, Whatsapp, enfim! Clientes da mesma forma! (E3).

[...]Relação de fornecedor, cliente! Me dê o seu produto e me dê o seu dinheiro. Tá entendendo? Não tem muito é... Relação assim boa comercialmente, tem que manter, mas é uma relação de qualquer empresa. Qualquer cliente e fornecedor, cumprir expectativas que eu vou continuar comprando de você tá entendendo? (E1)
}

Entende-se que uma sequência de eventos pode influenciar a mudança de estrutura a partir da inserção de práticas de sustentabilidade, contribuindo para uma formação de uma LIS (SILVA; FIGUEIREDO, 2017). Verificou-se que os estímulos tributários ocorridos em 2015 fomentaram a CS de energia solar, inserindo direta ou indiretamente práticas de sustentabilidade, a exemplo do evento da Resolução 687 que trouxe novas possibilidades à utilização de fontes de energia renovável pelo consumidor, quais sejam: Geração compartilhada; Autoconsumo remoto; e Empreendimento com múltiplas unidades consumidoras.

Buscando criar relações entre os atores da CS de energia solar, infere-se a partir das análises, que as práticas de sustentabilidade apresentam a possibilidade de serem institucionalizadas, apresentando indícios de que existem essas práticas no campo, o que poderá facilitar a formação de uma LIS, ressaltando os argumentos de Silva (2015) que menciona que as ações são socialmente construídas, formando uma nova lógica. Sobre essas práticas de sustentabilidade nos atores da díade da CS de energia solar, percebeu-se mais evidenciada a preocupação ambiental no cotidiano das ações ligadas à sustentabilidade da organização, apesar da região apresentar tendência para observar mais questões sociais (AZEVEDO et al., 2018). Essa comprovação pode ser observada na fala dos entrevistados: ANT1: "Existe um projeto que é o papel zero, reduzir a quantidade de papel nas agências". C3: "Coleta seletiva, a gente trabalha os $5 \mathrm{~S}$, a gente tentou te ligar os nossos recursos ao máximo sem desperdiçar, sem precisar comprar muito".

Não se pode deixar de evidenciar o que os entrevistados entendem por sustentabilidade. Dos dez entrevistados, três não tinham nenhuma noção do que significava o termo. Os demais responderam com pelo menos uma das dimensões do tripé de sustentabilidade, apontando, em sua maioria, o fator ambiental. Porém, apenas dois entendem completamente o conceito. Ainda assim, apesar do entendimento de sustentabilidade não estar em total consonância com o tripé de sustentabilidade proposto por Elkington (2002), as ações do dia a dia de algumas empresas dos entrevistados trazem a preocupação relacionadas às três dimensões. Esta visão ratifica Silva e Figueiredo (2020), que afirmam ser a sustentabilidade não o fim em si, mas uma prática performada ao longo do tempo. Assim, apesar de haver 
limitação no entendimento do que significa a sustentabilidade, foi possível identificar com a pesquisa que existem ações e mudanças que suportam a LIS.

\section{Considerações finais}

Com suporte no arcabouço teórico, verificou-se que a LIS apresenta indícios de um processo de formação no contexto analisado. Para a compreensão da formação da LIS houve indicações de mecanismos de mudança através das dimensões. Na dimensão sequência de eventos foram identificados eventos que impactaram o início da formação da LIS no contexto de CS de energia solar. Verificouse, ainda, que os eventos ligados à incentivos governamentais relativos à tributação foram os grandes aliados para o aumento da prática sustentável dirigida à energia solar. Em relação ao empreendedor institucional, destaca-se o Governo, com o papel de incentivar e regulamentar o uso de energia solar. Na dimensão mudança de estrutura, ocorridos por meio de mudanças na CS, a partir do Decreto 29.993/09 que regulamentou a Lei n.81/09, que criou o Fundo de Incentivo à Energia Solar do Estado do Ceará. Nota-se que novos valores, crenças, hábitos e normas vêm surgindo para estimular ações de sustentabilidade dentre todos os envolvidos no contexto analisado.

Ficou demonstrado que as empresas, apesar de em suas ações aplicarem a sustentabilidade de alguma forma, não a entendem como um tripé, existindo uma compreensão ainda pouco completa acerca do tema. A partir de suas falas, verificouse que atores, no cenário do Estado do Ceará, entendem a sustentabilidade como uma questão muito mais ligada à questão ambiental, afastando a ligação direta com a questão social e econômica. Porém, com a ocorrência de incentivos fiscais, quando a energia solar mostrou-se compensável economicamente, a sustentabilidade passou a valer a pena. Quanto à questão social, esta é ainda muito pouco lembrada quando se fala em sustentabilidade.

Não obstante das descobertas da pesquisa trazerem êxito, houve limitações no presente estudo. A pesquisa buscou compreender a formação de práticas sustentáveis apenas na relação díade empresa focal e cliente. Nesse sentido, outros atores inseridos na CS estudada não foram analisados. Ainda entende-se que enquanto estudo de caso os resultados não podem ser generalizados, mas podem ser transferidos para outros contextos. Sugere-se então, para pesquisas futuras um estudo abrangendo outros atores que compõe campo organizacional em estudo, bem como outras cadeias de suprimento no sentido de melhor entender a prática da sustentabilidade. Pesquisas quantitativas também podem ser desenvolvidas para tentar entender qual dimensão da LIS tem maior impacto no campo organizacional.

\section{Referências}

ABSOLAR. 2018. Disponível em: <http://www.absolar.org.br/noticia/noticiasexternas/energia-solar-possui-grande-potencial-de-expansao-no-ce.html>. Acesso em: 23 mar. 2018.

\section{ALVES, A. P. F. Dissemination of sustainability in supply chain: an analysis of} the contribution of a roundtable. Tese (Doutorado em Administração) - Programa de Pós-Graduação em Administração, Universidade Federal do Rio Grande do Sul, Porto Alegre. 2019. 
ALVES, A. P. F.; SILVA, M. E.; SANTOS, J. G. Colaboração para a sustentabilidade: Práticas de membros de uma cadeia de suprimentos do rio grande do sul. Revista de Gestão Social e Ambiental, v. 12, n. 1, p. 2-20. 2018.

ANTONELLO, C. S.; GODOY, A. S. A encruzilhada da aprendizagem organizacional: uma visão paradigmática. Revista de Administração Contemporânea, v. 14, n. 2, p. 310-332. 2010.

ARMIN RAZMJOO, A.; SUMPER, A.; DAVARPANAH, A. Energy sustainability analysis based on SDGs for developing countries. Energy Sources, Part A: Recovery, Utilization, and Environmental Effects, v. 42, n. 9, p. 1041-1056. 2020.

AZEVEDO, S. G., SILVA, M. E., MATIAS, J. C.; DIAS, G. P. The Influence of collaboration initiatives on the sustainability of the cashew supply chain. Sustainability, v. 10, n. 6, p. 2075. 2018.

BALLOU, R. H., GILBERT, S. M.; MUKHERJEE, A. New managerial, new challenges from supply chain opportunities. Industrial Marketing Management, v. 29, n. 1, p. 718. 2000.

BARATTER, M. A., FERREIRA, J. M.; COSTA, M. C. Empreendedorismo Institucional: características da ação intencional. Perspectivas Contemporâneas, ed. esp., p. 237266, 2010.

BARDIN, L. Análise de Conteúdo. Lisboa, Portugal; Edições 70. 2009.

BRITO, R. P.; BERARDI, P. C. Vantagem Competitiva na Gestão Sustentável da Cadeia de Suprimentoss: um metaestudo. RAE-Revista de Administração de Empresas, v. 50, n. 2, p. 155-169. 2010.

CARVALHO, C. A. P., VIEIRA, M. M. F.; LOPES, F. D. Perspectiva institucional para análise das organizações. In Anais... Encontro da ANPAD, Foz do Iguaçu.: CD-ROM. 1999.

CLARO, D. P. Managing business network and buyer-supplier relationship. Universal Press: Veenendal. 2004.

COSTA, A. O., OLIVEIRA, L. B., LINS, M. P. E., SILVA, A. C. M., ARAUJO, M. S. M., PEREIRA, A. O.; ROS, L. P. Sustainability analysis of biodiesel production: A review on different resources in Brazil. Renewable Sustainable Energy Rev., v. 27, p. 407412. 2013.

CRESWELL, J. W. Projeto de pesquisa: métodos qualitativo, quantitativo e misto. Porto Alegre: Artmed. 2007.

CRUZ, R. L.; ALENCAR, B. A.; SILVA, M. E. Ações de sustentabilidade em cadeias produtivas: uma pesquisa em relação à produção do caju e do coco. Revista Reuna, v. 22, n. 3, p. 1-18. 2017.

DENZIN, N. K.; LINCOLN, Y. S. (Eds.). Handbook of qualitative research. 2. ed. Thousand Oaks, Califórnia: Sage Publications. 2000. 
ELKINGTON, J. (Ed.). Cannibals with forks: the triple bottom line of 21st century business [reprint]. Oxford: Capstone. 2002.

FAGUNDES, M. V. C., FREIRES, F. G. M.; MARQUES, R. S. Gestão da cadeia de suprimentoss para sistemas de energia solar: conceitos e reflexões sobre a realidade brasileira. In Anais... Encontro Nacional de Engenharia de Produção, 36. 2016.

FEIL, A. A.; SCHREIBER, D. Sustentabilidade e desenvolvimento sustentável: desvendando as sobreposições e alcances de seus significados. Cadernos EBAPE.BR, v. 15, n. 3, p. 667-681, 2017.

FERNANDO, Y.; BEE, P. S.; JABBOUR, C. J. C.; THOMÉ, A. M. T. Understanding the effects of energy management practices on renewable energy supply chains: Implications for energy policy in emerging economies. Energy Policy, v. 118, p. 418428, 2018.

FRIEDLAND, R.; ALFORD, R. R. Bringing Society back it: symbols, practices and institutional contradictions. In: Powell, W. W.; DiMaggio, P. J. (Eds.). The new institutionalism in organizational analysis. Chicago: University of Chicago Press. 1991.

GIL, A. C. Como elaborar projetos de pesquisa. 5. ed. São Paulo: Atlas. 2010.

GODOY, A. S. Estudo de caso qualitativo In: Godoi, C. K.; Bandeira-de-Mello, R.; Silva, A. (Org.). Pesquisa qualitativa em estudos organizacionais. São Paulo: Saraiva. 2006.

KULAK, C. M.; STEFANO, S. R.; KUHL, M. R. Institucionalização de práticas de sustentabilidade. Revista Reuna, v. 24, n. 2, p. 67-88, 2019.

LAWRENCE, T. B.; PHILLIPS, N. From Moby Dick to Free Willy: macro-cultural discourse and institutional entrepreneurship in emerging institutional fields. Organization, v. 11, n. 5, p. 689-711, 2004.

MALONI, M. J.; BENTON, W. C. Supply chain partnerships: opportunities for operations research. European Journal of Operational Research, v. 101, n. 3, p. 419-429, 1997.

MENTZER, J. T., DEWITT, W., KEEBLER, J. S., MIN, S., NIX, N. W., SMITH, C.; ZACHARIA, Z. G. Definind Suplly Chain Management. Journal of Business Logisticis, v. 22, n. 2, p. 1-25. 2001.

MIN, S., ZACHARIA, Z. G.; SMITH, C. D. Defining supply chain management: in the past, present, and future. Journal of Business Logistics, v. 40, n. 1, p. 44-55. 2019.

MORAIS, D. O. C.; OLIVEIRA, N. Q.; SOUZA, E. M. As práticas de sustentabilidade ambiental e suas influências na nova formatação institucional das organizações. Revista de Gestão Ambiental e Sustentabilidade, v. 3, n. 3, p. 90-106. 2014.

MUNCK, L., DIAS, B. G.; DE SOUZA, R. Sustentabilidade organizacional: uma análise a partir da institucionalização de práticas ecoeficientes. REBRAE - Revista Brasileira 
de Estratégia, v. 1, n. 3, p. 285-295. 2008.

PEREIRA, R. C. F.; BELLINI, C. G. P. A perspectiva da díade em relacionamentos entre empresas e clientes de software. In Anais... Encontro da ANPAD, Salvador. 2006.

Portal Solar. (2018). Energia Solar é a Fonte Energética que mais cresce no Mundo. Disponível em: <https://www.portalsolar.com.br/blog-solar/energiasolar/energia-solar-e-a-fonte-energetica-que-mais-cresce-no-mundo.html>. Acesso em: 5 fev. 2018.

RECHENE, S. T., SILVA, M. E.; CAMPOS, S. A. P. Sharing Economy and Sustainability Logic: Analyzing the use of Shared Bikes. Brazilian Administration Review - BAR, v. 15, n. 3, p. 1-13, 2018.

SANTOS, H.; LANNELONGUE, G.; GONZALEZ-BENITO, J. Integrating green practices into operational performance: evidence from Brazilian manufacturers. Sustainability, v. 11, n. 10, 2956. 2019.

SARTORI, S., LATRÔNICO, F.; CAMPOS, L. M. S. Sustentabilidade e desenvolvimento sustentável: uma taxonomia no campo da literatura. Ambiente e Sociedade, v. 17, n. 1, p. 1-22 2014.

SAYED, M., HENDRY, L. C.; BELL, M. Z. Institutional complexity and sustainable supply chain management practices. Supply Chain Management: An International Journal, v. 22, n. 6, p. 542-563, 2017.

SEBRAE. Cadeia de Valor de Energia Solar Fotovoltaica no Brasil. 2017. Brasília. Disponível em: www.sebrae.com.br, acesso em: Novembro/2004. Acesso em: 23 mar. 2018.

SEURING, S.; MÜLLER, M. From a literature review to a conceptual framework for sustainable supply chain management. Journal of Cleaner Production, v. 16, n. 15, p. 1699-1710. 2008.

SILVA, M. E. A formação da Lógica Institucional da Sustentabilidade em Cadeias de Suprimentos: um estudo no Brasil e no Reino Unido. 2015, 260 p. Tese (Doutorado em Administração) - Programa de Pós-Graduação em Administração, Universidade Federal do Rio Grande do Sul, Porto Alegre. 2015.

SILVA, M. E., COSTA, A. C. V.; GÓMEZ, C. P. Sustentabilidade no Terceiro Setor: O desafio de harmonizar as dimensões da sustentabilidade em uma ONG. Revista Reuna, v.16, n. 3, 2011.

SILVA, M.; FIGUEIREDO, M. Sustainability as practice: Reflections on the creation of an institutional logic. Sustainability, v. 9, n. 10, 1839. 2017.

SILVA, M. E.; FIGUEIREDO, M. D. Practicing sustainability for responsible business in supply chains. Journal of Cleaner Production, v. 251, 119621. 2020. 
SILVA, M. E.; NASCIMENTO, L. F. Análise institucional para a sustentabilidade em cadeias de suprimento no Brasil e no Reino Unido. Amazônia, Organizações e Sustentabilidade, v. 6, n. 2, 2017.

SILVESTRE, B. S. Sustainable supply chain management in emerging economies: Environmental turbulence, institutional voids and sustainability trajectories. International Journal of Production Economics, v. 167, p. 156-169. 2015.

SOARES, R. R. A Sustentabilidade aplicada na Elaboração de Centros de Distribuição no Brasil. Revista de Gestão Ambiental e Sustentabilidade - GeAS, v. 6, n. 3, 2017.

STÅL, H. I. Inertia and change related to sustainability-An institutional approach. Journal of Cleaner Production, v. 99, p. 354-365. 2015.

TOUBOLIC, A.; WALKER, H. Theories in sustainable supply chain management: a structured literature review. International Journal of Physical Distribution \& Logistics Management, v. 45, (1/2). 2015.

THORNTON, P. H.; JONES, C; KURY, K. Institutional logic and institutional change in organizations: transformation in accounting, archictecture and publishing. In: JONES, C.; THORTON, P. H. (Eds.). Research in the Sociology of Organizations. Local: Editora, 2005.

THORNTON, P. H.; OCASIO, W. Institutional Logics. The Sage Handbook of Organizational Institutionalism, 99-129. 2008.

THORNTON, P. H.; OCASIO, W. Institutional Logics and the Historical Contingency of Power in Organizations: Executive Succession in the Higher Education Publishing Industry, 1958- 1990 1. American Journal of Sociology, v. 105, n. 3, p. 801-843, 1999.

VERGARA, S. Métodos de pesquisa em administração. 4. ed. São Paulo: Atlas. 2010.

YIN, R. K. Estudo de Caso: Planejamento e Métodos. Porto Alegre: Bookman. 2015. 